\title{
Successful production of offspring after superovulation and in vitro culture of embryos from domestic ferrets (Mustela putorius furos)
}

\author{
Z. Y. Li ${ }^{1 *}$, Q. S. Jiang ${ }^{1 * \dagger}$, Y. L. Zhang ${ }^{1,3}$, X. M. Liu ${ }^{1}$ \\ and J. F. Engelhardt1,2,3 \\ ${ }^{1}$ Departments of Anatomy and Cell Biology, College of Medicine, The University of lowa, \\ Iowa City, IA 52242, USA; ${ }^{2}$ Internal Medicine, College of Medicine, The University of lowa, \\ lowa City, IA 52242, USA; and ${ }^{3}$ The Center for Gene Therapy of Cystic Fibrosis and Other \\ Genetic Diseases, College of Medicine, The University of lowa, lowa City, IA 52242, USA
}

In an effort to expand the use of ferrets as models for genetic disease, several experimental parameters that are required for successful genetic manipulation in this species were investigated. Optimum superovulation (19.3 \pm 0.6 oocytes and embryos per female) was achieved after injections of 100 iu equine chorionic gonadotrophin (eCG) and 150 iu human chorionic gonadotrophin (hCG). The ovulation rate achieved by the treatment was more than double that induced by mating. Mating with a male immediately after hCG treatment did not significantly alter the number of oocytes ovulated or the number of embryos present, indicating that mating is not required for superovulation in ferrets. Of embryos harvested at the one-cell stage, $64.5 \%$ and $47.1 \%$ developed into blasto- cysts when cultured in vitro in CZB or TCM-199 plus $10 \%$ fetal bovine serum (FBS) media, respectively. In contrast, only $17.1 \%$ of embryos cultured in vitro in NCSU-23 developed to the blastocyst stage. Both freshly retrieved and in vitro cultured embryos from cinnamoncoloured parents produced live young when transferred at the eight-cell stage into albino, pseudopregnant recipients. The percentage of kits delivered relative to embryos transferred was $61 \%$ for freshly retrieved embryos and $32 \%$ for embryos cultured in vitro. These results demonstrate successful embryo transfer in ferrets and provide a basis for further study of genetic modelling approaches in this species after embryo manipulation.

\section{Introduction}

The domestic ferret (Mustela putorius furos) has become an excellent model for biomedical studies in areas such as infectious diseases, neurological disorders and reproductive biology. Other studies have revealed that ferrets have marked similarities to humans in airway structure and cell biology (Plopper et al., 1980; Leigh et al., 1986; Curtis et al., 1987; Sehgal et al., 1996; Duan et al., 1998). Furthermore, ferrets are a useful model for the study of lung infections caused by viruses such as influenza (Husseini et al., 1983; Durchfeld et al., 1991; Jakeman et al., 1991; Leigh et al., 1995; Fenton et al., 1999). These studies indicate that ferrets may serve as an excellent animal model for the study of airway diseases in humans. Ongoing research in our laboratory has the eventual goal of generating a ferret model for the study of cystic fibrosis, an inherited disorder affecting about 1 in every 3000 newborns among the Caucasian population. The present study describes embryo manipulation in ferrets, as a prelude to initiating genetic modelling approaches in this species.

\footnotetext{
*These authors contributed equally to this work

${ }^{+}$Correspondence

Email: qinshi-jiang@uiowa.edu
}

Natural ovulation in ferrets is induced by mating and occurs 24-36 h thereafter (Robinson, 1918; Hammond and Marshall, 1934). In the absence of any hormonal treatment, a virgin female in oestrus generally ovulates six to ten oocytes after mating with a male (Chang, 1965; Mead et al., 1988). To date, only a few studies have investigated the effects of hormonal treatment on ovulation in ferrets, and none of these has achieved very high ovulation rates (Chang, 1965; Mead et al., 1988; Amstislavskii et al., 1997). Therefore, a more detailed investigation using different combinations of gonadotrophins is required to maximize the number of oocytes and embryos that can be retrieved from individual female ferrets.

The first successful embryo transfer was performed in rabbits (Heape, 1890), and has since been applied to a variety of domestic and wild animals (Day, 1979; Kreamer et al., 1979; Dickman, 1982; Moor, 1982; Newcomb, 1982; Nicholas, 1993), including ferrets (Chang, 1968; Kidder et al., 1999b). However, there are no reports of embryo transfer in ferrets using embryos developed in vitro. The ability to culture ferret embryos in vitro and to produce live offspring by embryo transfer is critical for genetic manipulation of this species and the subsequent development of new animal models for human diseases. 


\section{Materials and Methods}

\section{Animals and housing conditions}

Ferrets (6-24 months of age) with cinnamon- or albinocoloured coats were purchased from Marshall Farms (North Rose, NY). Female ferrets were in oestrus when delivered and non-vasectomized males were proven breeders. Four vasectomized male ferrets were also purchased from Marshall Farms and were used to induce pseudopregnancy in females. After vasectomy, each male was mated repeatedly before a sperm count was carried out to confirm the sterile state of the animal. Sterility, as inferred by aspermia and the lack of pregnancy after three sequential matings with an oestrous jill, was confirmed within 3 months of vasectomy in all four males. All ferrets were housed in separate cages under controlled temperature $\left(20-22^{\circ} \mathrm{C}\right)$ and long day light cycles (16 h light:8 h dark).

\section{Superovulation of ferrets}

For superovulation, virgin female ferrets were injected i.p. with 50-150 iu eCG (Sigma G-4877; also referred to as PMSG), followed by an injection of 50-200 iu hCG (Sigma, C-1063) $72 \mathrm{~h}$ later. Virgin females were used because the litter size, and presumably the number of oocytes ovulated, decreases with subsequent pregnancies (McLain et al., 1985). Each female was mated with one male or with two males in succession immediately after hCG treatment when embryos rather than haploid oocytes were needed. In experiments performed to determine the effect of mating on superovulation in ferrets, females were mated with vasectomized males. Female ferrets were subsequently killed by administration of an overdose of barbiturates (pentobarbital sodium administered i.p. at 50-100 $\mathrm{mg} \mathrm{kg}^{-1}$ body weight) so that oocytes or embryos could be harvested. The ovaries, oviducts and sections of the uterine horns were removed, and oocytes or embryos were flushed from the oviducts or uterine horns with Dulbecco's PBS (DPBS; $0.1 \mathrm{~g} \mathrm{CaCl}_{2}$ (anhyd) $\mathrm{I}^{-1}$, $0.2 \mathrm{~g} \mathrm{KCl} \mathrm{I}^{-1}, 0.2 \mathrm{~g} \mathrm{KH}_{2} \mathrm{PO}_{4}$ (anhyd) I-1, $0.1 \mathrm{~g} \mathrm{MgCl}_{2} \cdot 6 \mathrm{H}_{2} \mathrm{O}$ $\left.\mathrm{I}^{-1}, 8.0 \mathrm{~g} \mathrm{NaCl} \mathrm{I}^{-1}, 2.16 \mathrm{~g} \mathrm{Na}_{2} \mathrm{HPO}_{4} \cdot 7 \mathrm{H}_{2} \mathrm{O} \mathrm{I}^{-1}\right)+2 \%(\mathrm{v} / \mathrm{v})$ newborn calf serum (NCS; Sigma, N-4762).

\section{Culture of ferret embryos}

One- or two-cell embryos harvested from two or three superovulated, mated jills were divided evenly into three groups. The three groups of embryos were cultured simultaneously in one of the three types of medium: (i) TCM-199 + 10\% FBS; (ii) NCSU-23 (Petters and Reed, 1991); and (iii) CZB (81.62 mmol NaCl I-1; $4.83 \mathrm{mmol} \mathrm{KCl}$ $\mathrm{I}^{-1} ; 1.18 \mathrm{mmol} \mathrm{KH}_{2} \mathrm{PO}_{4} \mathrm{I}^{-1}, 1.18 \mathrm{mmol} \mathrm{MgSO} \cdot 7 \mathrm{H}_{2} \mathrm{O} \mathrm{I}^{-1}$; $25.12 \mathrm{mmol} \mathrm{NaHCO}_{3} \mathrm{I}^{-1} ; 1.70 \mathrm{mmol} \mathrm{CaCl}_{2} \cdot 2 \mathrm{H}_{2} \mathrm{O} \mathrm{I}{ }^{-1}$; $31.30 \mathrm{mmol}$ sodium lactate $\mathrm{I}^{-1}$; $0.27 \mathrm{mmol}$ sodium pyruvate $\mathrm{I}^{-1} ; 0.11 \mathrm{mmol}$ EDTA (disodium salt) $\mathrm{I}^{-1} ; 1.0 \mathrm{mmol}$ glutamine $\mathrm{I}^{-1} ; 5.0 \mathrm{mg} \mathrm{BSA} \mathrm{ml}^{-1}, 100$ iu penicillin $\mathrm{G}$ sodium salt $\mathrm{ml}^{-1} ; 0.7 \mathrm{mg}$ streptomycin $\mathrm{ml}^{-1}$ ) (Chatot et al., 1989). Repeated experiments were performed until a cumulative set of oocytes was derived from the total of nine individual ferrets. Groups of five to ten embryos were placed in droplets of medium, covered with embryo culture grade mineral oil, and incubated at $38.5^{\circ} \mathrm{C}$ under $5 \% \mathrm{CO}_{2}$ and $95 \%$ air. Fresh medium was delivered to the embryos every $48 \mathrm{~h}$ and their development was examined under an inverted phase-contrast microscope. Embryos arrested at different stages of cleavage were recorded and quantitated for statistical analyses. Some of the in vitro cultured embryos at different stages of development were stained with $10 \mu \mathrm{g}$ bisbenzimide $\mathrm{ml}^{-1}$ (Hoechst 33342, Sigma B2261) for 2-5 min before examination under UV.

\section{Embryo transfer}

Experienced jills only were used as recipients in embryo transfer studies to exclude the possibility of infertility among surrogate mothers. A pseudopregnant state was achieved in recipient albino females mated with vasectomized albino males 12-24 h after cinnamon-coloured jills (embryo donors) were mated. The time lag between the mating of donor and recipient jills ensured synchronization between the donors and recipients, as in vitro manipulation of embryos generally causes a developmental delay. Embryos developed in vivo were harvested from cinnamon-coloured jills at day 4 after mating and were at the 8-16-cell stage. These embryos were collected in warmed $\left(38.5^{\circ} \mathrm{C}\right) \mathrm{mPBS}$ (DPBS supplemented with $0.1 \%$ (w/v) D-glucose, $36 \mathrm{mg}$ pyruvate $\mathrm{I}^{-1}$ and $\left.0.4 \% \quad \mathrm{BSA}\right)$ and were transferred immediately into the uterine horn of a surrogate albino female. Embryos collected from cinnamon-coloured females at the one-cell stage, 36-40 h after mating, were cultured in TCM-199 $+10 \%$ FBS to the 8-16-cell stage before they were transferred to a recipient female. On the day of transfer, the recipient albino female was anaesthetized by an injection of $25 \mathrm{mg}$ ketamine $\mathrm{kg}^{-1}$ and $4 \mathrm{mg}$ xylazine $\mathrm{kg}^{-1}$. A 3-4 cm incision was made along the midline of the abdomen to expose the uterus and the uterine horns. Between 6 and 19 embryos were delivered into the left uterine horn using a fine glass pipette with an inner diameter slightly larger than the embryos. After the surgical wound was sutured, the ferret was allowed to wake up in its own cage under close monitoring. Confirmation of pregnancy was performed by palpation 2-4 weeks after transplantation. The number of kits produced was recorded on the morning after parturition and again at weaning, 7 weeks later. The coat colour of the kits was used to confirm their genetic lineage.

\section{Statistical analyses}

Mean variances among different sample groups were determined by ANOVA. Comparison between two sample groups was made by the Student's $t$ test. A significant difference was found when the $P$ value was $<0.05$.

\section{Results}

Domestic ferrets living in the wild normally give birth to 
Table 1. The effectiveness of different doses of eCG and hCG in inducing ovulation in domestic ferrets during oestrus

\begin{tabular}{|c|c|c|c|c|c|c|}
\hline \multirow[b]{2}{*}{$\begin{array}{l}\text { Treatment } \\
\text { (iu eCG/iu hCG) }\end{array}$} & \multicolumn{3}{|c|}{$\begin{array}{l}\text { Short-term study } \\
\text { (6 weeks) }\end{array}$} & \multicolumn{3}{|c|}{$\begin{array}{l}\text { Long-term study } \\
\text { (1 year) }\end{array}$} \\
\hline & $\begin{array}{l}\text { Number of } \\
\text { ferrets }^{\mathrm{d}}\end{array}$ & $\begin{array}{c}\text { Total number } \\
\text { of oocytes }\end{array}$ & $\begin{array}{c}\text { Number of oocytes } \\
\text { per jill } \\
(\text { mean } \pm \text { SEM })^{\mathrm{e}}\end{array}$ & $\begin{array}{l}\text { Number of } \\
\text { ferrets }^{\mathrm{d}}\end{array}$ & $\begin{array}{c}\text { Total number } \\
\text { of oocytes }\end{array}$ & $\begin{array}{c}\text { Number of } \\
\text { oocytes per jill } \\
\text { (mean } \pm \text { SEM) }^{\mathrm{e}}\end{array}$ \\
\hline $0 / 0$ & 3 & 18 & $6.0 \pm 1.2^{\mathrm{a}}$ & 7 & 62 & $8.9 \pm 2.5^{\mathrm{a}}$ \\
\hline $50 / 50$ & 3 & 19 & $6.3 \pm 0.7^{a}$ & 3 & 19 & $6.3 \pm 0.7^{a}$ \\
\hline $100 / 100$ & 3 & 60 & $20.0 \pm 1.7^{c}$ & 3 & 60 & $20 \pm 1.7^{c}$ \\
\hline $100 / 150$ & 3 & 56 & $18.7 \pm 2.3^{c}$ & 20 & 397 & $19.9 \pm 1.1^{c}$ \\
\hline $150 / 150$ & 3 & 45 & $15.0 \pm 3.1^{b}$ & 9 & 135 & $15.0 \pm 1.0^{b}$ \\
\hline $150 / 200$ & 3 & 46 & $15.3 \pm 1.5^{c}$ & 6 & 100 & $16.7 \pm 0.9^{c}$ \\
\hline
\end{tabular}

abcWithin groups, values with the same letter are not significantly different in the superovulation rate $(P>0.05)$.

dAll jills that were not treated with gonadotrophins were in oestrus and mated to stud males. All other jills treated with various doses of gonadotrophins were not mated and were in oestrus at the time of ovulation.

eMean number of oocytes or embryos recovered from the Fallopian tubes and uterus 36-40 h after administration of hCG or mating.

between six and ten kits per litter. The present study investigated whether treatment with eCG to induce follicular maturation, followed by injection of hCG to induce ovulation, could increase the number of oocytes and embryos harvested from a single unmated oestrous female. In an initial set of experiments, cinnamon-coloured virgin female ferrets were allocated randomly into six treatment groups so that each group contained three animals with equivalent breeding background and reproductive status. Oocytes were harvested at $36 \mathrm{~h}$ after gonadotrophin treatment or mating (for untreated animals only) to ensure that most of the matured oocytes were ovulated. Results from these studies indicated that there was a significant increase in the ovulation rate when the concentration of gonadotrophins was increased from 50 iu eCG and $50 \mathrm{iu}$ hCG $(6.3 \pm 0.7)$ to $100 \mathrm{iu}$ eCG and $100 \mathrm{iu}$ hCG (20.0 \pm 1.7$)$. Treatment with higher doses of eCG and hCG did not result in a further increase in the ovulation rate (Table 1). On the basis of the results from the initial set of experiments, a combination of 100 iu eCG and 150 iu hCG was chosen as the treatment for subsequent experiments. Data obtained from the initial phase of the experiments (in which three animals were included in each treatment group) were compared with a more comprehensive set of data from a long-term study over 1 year (Table 1). In the long-term study, oocytes were harvested at $36-40 \mathrm{~h}$ after gonadotrophin treatment or mating (for untreated animals only). In the long-term study, mating of untreated virgin ferrets in oestrus with stud males resulted in an ovulation rate of $8.9 \pm 2.5$ oocytes per female. Treatment with gonadotrophins at the lowest concentrations, a combination of 50 iu eCG and 50 iu hCG, resulted in an ovulation rate of $6.3 \pm 0.7$ oocytes from each female in the absence of mating, which did not differ significantly from untreated, mated females. Treatment with high doses of gonadotrophins, 150-200 iu of both eCG and hCG, resulted in more variable ovulation rates ranging from $15.0 \pm 1.0$ to
$18.0 \pm 1.2$ oocytes from each unmated female. At intermediate doses of 100 iu eCG and 100 iu hCG, and 100 iu eCG and 150 iu hCG, ovulation rates were $20.0 \pm 1.7$ and $19.9 \pm 1.1$ oocytes, respectively. These results are in agreement with those obtained from the smaller number of animals in the initial phase of the study.

As mating induces ovulation in ferrets, the present study next investigated whether mating increases the number of oocytes obtained after hormonal treatment. According to previous studies (Table 1), it is apparent that mating is not the only factor responsible for ovulation. However, whether mating would increase superovulation rates further remains to be addressed. In an attempt to answer this question, two groups of oestrous jills were treated with eCG and hCG at two doses. One group of ferrets was mated with vasectomized males immediately after the hCG treatment, whereas the second group received hormone treatment only. In preliminary short-term studies, equal numbers of animals were evaluated in each of the four treatment groups (Table 2) until a total of three animals was obtained in each group. These studies were performed over a period of 4 weeks and the number of oocytes harvested from mated females at $36-40 \mathrm{~h}$ after mating was compared with the numbers of oocytes recovered from non-mated, hormonetreated females. The results obtained from this initial shortterm study with matched numbers of jills, and data from our experiments performed over 1 year are shown (Table 2). A combination of either 100 iu eCG and 150 iu hCG or 150 iu eCG and 200 iu hCG did not result in significant differences between the mated and non-mated groups. These experiments demonstrated that mating does not significantly augment hormonal superovulation in ferrets. However, it was only possible to induce superovulation in oestrous ferrets, as nursing ferrets at 8 weeks after delivery produced only up to three oocytes despite treatment with eCG and hCG (data not shown).

The effects of different culture media on the in vitro 
Table 2. Effect of mating on eCG- and hCG-induced ovulation in domestic ferrets during oestrus

\begin{tabular}{|c|c|c|c|c|c|c|c|}
\hline \multirow[b]{2}{*}{$\begin{array}{l}\text { Treatment } \\
\text { (iu eCG/iu } \\
\text { hCG) }\end{array}$} & \multirow[b]{2}{*}{ Mating } & \multicolumn{3}{|c|}{$\begin{array}{l}\text { Short-term study } \\
\quad(4 \text { weeks })\end{array}$} & \multicolumn{3}{|c|}{$\begin{array}{l}\text { Long-term study } \\
\text { (1 year) }\end{array}$} \\
\hline & & $\begin{array}{l}\text { Number of } \\
\text { ferrets }\end{array}$ & $\begin{array}{c}\text { Total number of } \\
\text { oocytes or } \\
\text { embryos }\end{array}$ & $\begin{array}{c}\text { Number of oocytes } \\
\text { or embryos per jill } \\
\text { (mean } \pm \text { SEM)* }\end{array}$ & $\begin{array}{l}\text { Number of } \\
\text { ferrets }\end{array}$ & $\begin{array}{c}\text { Total number of } \\
\text { oocytes or } \\
\text { embryos }\end{array}$ & $\begin{array}{c}\text { Number of oocytes } \\
\text { or embryos per jill } \\
\quad(\text { mean } \pm \text { SEM)* }\end{array}$ \\
\hline \multirow[t]{2}{*}{$100 / 150$} & No & 3 & 56 & $18.7 \pm 2.3$ & 20 & 397 & $19.9 \pm 1.1$ \\
\hline & Yes & 3 & 62 & $20.7 \pm 0.9$ & 24 & 453 & $18.9 \pm 0.6$ \\
\hline \multirow[t]{2}{*}{$150 / 200$} & No & 3 & 50 & $16.7 \pm 0.9$ & 6 & 100 & $16.7 \pm 0.9$ \\
\hline & Yes & 3 & 54 & $18.0 \pm 2.5$ & 4 & 80 & $20.0 \pm 2.7$ \\
\hline
\end{tabular}

*Mean number of oocytes or embryos recovered from the Fallopian tubes and uterus 36-40 h after the injection of hCG or mating.

development of ferret embryos recovered from superovulated, virgin females in oestrus that had been mated to stud males were examined. Most of the embryos used for studies in vitro were harvested at the one-cell stage. However, occasionally, embryos at the two-cell stage were also used. The sequential developmental stages of ferret embryos with reference to the time after hCG treatment are shown (Fig. 1). Of the embryos cultured in CZB medium, $64.5 \%$ developed to the morula stage 6-7 days after hCG treatment (Fig. 1; Table 3), and the same percentage of embryos developed to the blastocyst stage under these culture conditions. When TCM-199 medium supplemented with $10 \%$ FBS was used, $70.6 \%$ and $47.1 \%$ of cultured embryos developed into morulae and blastocysts, respectively. Although embryonic development in CZB and TCM-199 was largely similar, blastocyst formation occurred about $12 \mathrm{~h}$ earlier in TCM-199. Significantly fewer embryos developed to morula (28.6\%) and blastocyst (17.1\%) stages when cultured in the NCSU-23 medium. Several embryos were stained with Hoechst 33342 to determine whether embryos cultured in vitro had developed properly. Hoechst 33342 staining of embryos at the eight-cell, $\geqslant 16$-cell and blastocyst stages revealed numbers of nuclei corresponding to the developmental stages observed using light microscopy (Fig. 1). When the numbers of nuclei were counted in four in vitro cultured blastocysts, an average of $87.5 \pm 19.2$ nuclei per embryo was found (data not shown).

Embryo transfer was performed using ferrets with cinnamon-coloured coats as embryo donors and ferrets with albino-coloured coats mated with vasectomized albino males as recipients. In three of a total of six embryo transfer experiments, freshly retrieved 8-16-cell embryos were transferred immediately to the uterine horn of the recipient. All embryos harvested from donor jills were at the 8-16-cell stage and were of normal morphology. No deteriorated oocytes or dead embryos were recovered. All three female recipients became pregnant, and 61\% (33 of 54) of the embryos transferred developed to term (Table 4). The average litter size was $11 \pm 5$. Fifty per cent (27 of 54) of the transferred embryos produced live kits at birth, of which $26 \%$ (14 of 54 ) survived beyond week 8 (at which time the experiment was terminated). Three additional embryo transfer experiments were performed using embryos cultured in vitro. In these experiments, embryos were harvested at the one- or two-cell stage and were cultured in TCM-199 + 10\% FBS media for 3 days, by which time most of the embryos had developed to the eight-cell stage. Embryos of normal morphology were then transferred to albino female recipients. All three female recipients became pregnant and $32 \%$ (12 of 38) of the transferred embryos developed to term (Table 4). The average litter size was $4 \pm 2$. Only $21 \%$ (8 of 38 ) of the transferred embryos resulted in live kits at birth, of which $16 \%$ (6 of 38) survived beyond week 8 of weaning. In all cases, the kits from both experimental groups (in vivo and in vitro matured embryos) were born with pink-coloured skin, and all kits surviving to or beyond 18 days after birth showed an obvious cinnamon-coloured coat (Fig. 2).

\section{Discussion}

Superovulation, embryo culture and embryo transfer were investigated in ferrets as a prerequisite to embryo manipulation and the development of ferret models for the study of genetic diseases such as cystic fibrosis. The results of this study demonstrate that treatment of domestic ferrets in oestrus with an optimum combination of eCG (100 iu) and hCG (150 iu) administered at an interval of $72 \mathrm{~h}$ induced an ovulation rate that was more than double that achieved by mating. The average number of oocytes (19.9) that could be harvested from the oviducts and uterine horns was significantly greater than the numbers reported in ferrets treated with $90 \mathrm{iu}$ hCG alone (Chang, 1965; Mead et al., 1988). The mean number of oocytes produced varied significantly (as determined by ANOVA) between the experimental group receiving 100 iu eCG and 150 iu hCG and the groups receiving higher doses of eCG and hCG. However, there was no significant decrease in the rate of ovulation at a dose of 200 iu hCG. This finding is in contrast to a report by Mead et al. (1988) in which higher doses (150 or $300 \mathrm{iu}$ ) of hCG resulted in a decrease in the average number of corpora lutea formed. Results from the present 

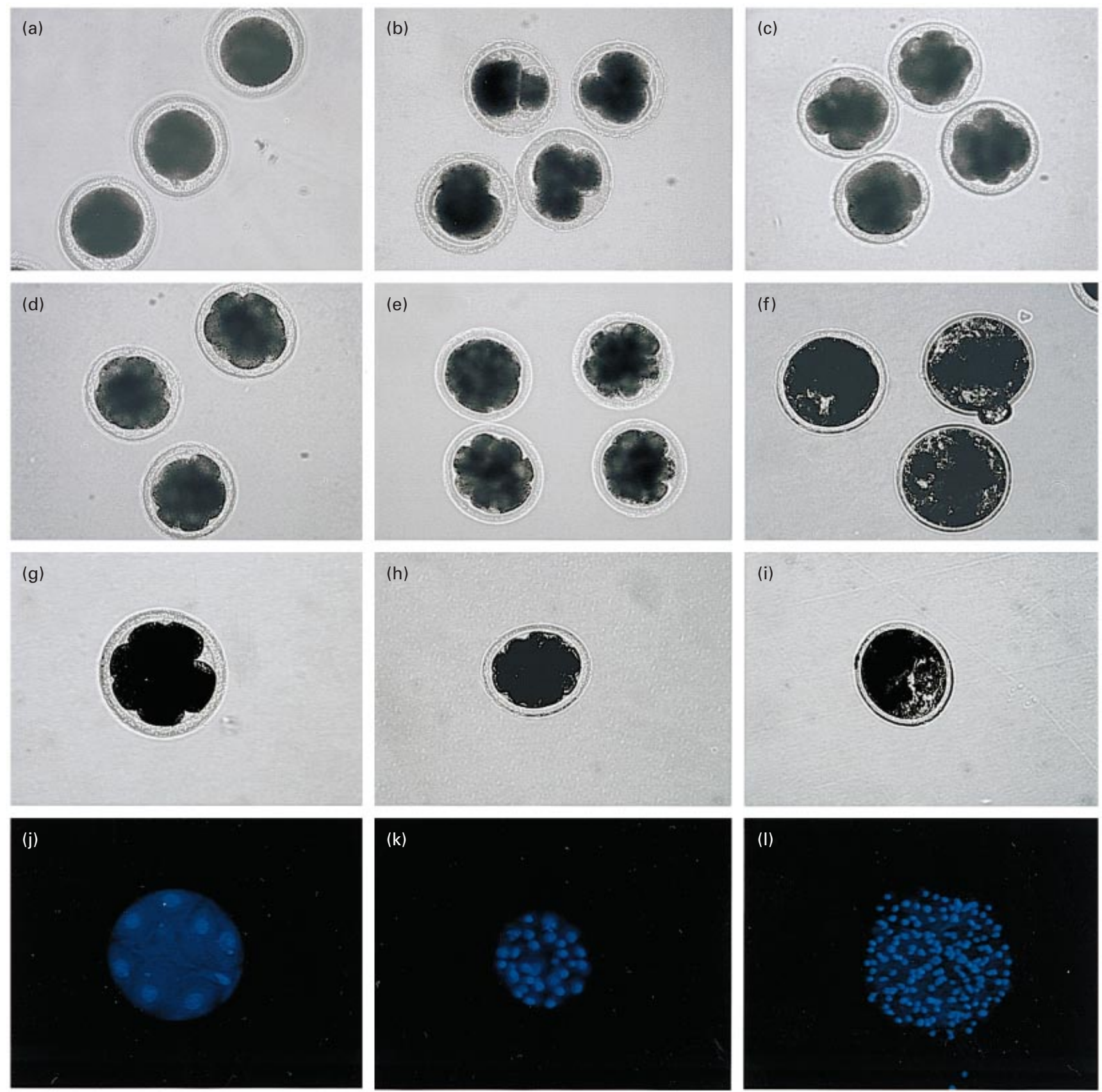

Fig. 1. Ferret oocytes and embryos at different stages of development. Fertilized oocytes at the pronuclear stage were harvested $40 \mathrm{~h}$ after hCG injection from mated cinnamon-coloured females that had been treated with eCG and hCG to induce superovulation. Embryos were cultured in vitro in TCM199/FBS medium. One-cell embryos at harvest (a). In vitro cultured embryos at the (b) two- to four-cell stage (day 3 after mating), (c) five- to eight-cell stage (day 4 after mating), (d) 9-16-cell stage (day 5 after mating), (e) 17-32-cell (morula) stage (day 6 after mating) and ( $\mathrm{f}$ ) blastocyst stage (> day 7 after mating). (g-l) Hoechst 33342 stained nuclei of individual blastomeres from ferret embryos cultured in vitro. Embryos at the eight-cell stage (g,j), 30-cell stage (h,k) and blastocyst stage (126 cells) $(\mathrm{i}, \mathrm{I})$. Nomarski images shown in $(\mathrm{g})$, (h) and (i) correspond to Hoechst-stained embryos in (j), (k) and (l), respectively. Note that a coverslip was placed on the Hoechst-stained embryos to flatten the tissues so that all blastomere nuclei could be visualized in one plane of focus; hence, position of nuclei in Nomarski images without coverslips does not correlate with fluorescent images.

study also demonstrated that mating does not significantly augment hormonal superovulation in ferrets. A treatment regimen of 100 iu eCG and 150 iu hCG was chosen in all of our downstream studies primarily due to the fact that high doses of gonadotrophins can adversely affect the quality of superovulated oocytes or embryos, and the proper 
Table 3. Effect of different culture media on development of ferret embryos in vitro

\begin{tabular}{|c|c|c|c|c|c|}
\hline \multirow[b]{2}{*}{ Medium } & \multirow{2}{*}{$\begin{array}{l}\text { Number of } \\
\text { embryos }^{\mathrm{a}}\end{array}$} & \multicolumn{2}{|c|}{$\begin{array}{c}\text { Morulae } \\
\text { (6 days after hCG) }\end{array}$} & \multicolumn{2}{|c|}{$\begin{array}{c}\text { Blastocysts } \\
(>7 \text { days after } \mathrm{hCG})\end{array}$} \\
\hline & & Number & $\%$ & Number & $\%$ \\
\hline CZB & 31 & 20 & 64.5 & 20 & 64.5 \\
\hline NCSU-23 & 35 & 10 & 28.6 & 6 & 17.1 \\
\hline TCM199+ 10\% FBS & 34 & 24 & 70.6 & 16 & 47.1 \\
\hline
\end{tabular}

aOnly one- or two-cell embryos of normal morphology were used for analysis.

Embryos were derived from nine independent jills.

Table 4. Embryo transfer in domestic ferrets

\begin{tabular}{|c|c|c|c|c|c|c|}
\hline & \multicolumn{6}{|c|}{ Experiment number } \\
\hline & 1 & 2 & 3 & 4 & 5 & 6 \\
\hline Embryos cultured in vitro & No & No & No & Yes & Yes & Yes \\
\hline Number of embryos transferred & 19 & 17 & 18 & 6 & 16 & 16 \\
\hline Number of live kits & 13 & 3 & 11 & 6 & 0 & 2 \\
\hline Number of dead kits & 3 & 3 & 0 & 0 & 2 & 2 \\
\hline Number of live kits at week 8 post partum & 5 & 3 & 6 & 6 & 0 & 0 \\
\hline
\end{tabular}

All embryos were harvested from cinnamon-coloured female ferrets mated with males of the same colour. All recipients of embryo transfer were albino. Embryos developed in vivo were harvested at the eight-cell stage and were transferred immediately. Embryos developed in vitro were harvested at the one- to two-cell stage and were cultured until they reached the eight-cell stage before being transferred to the recipients. All six embryo transfer experiments resulted in pregnancy of recipient albino females.

development of embryos (Whyman and Moore, 1980; Moor et al., 1985; Ertzeid and Storeng, 1992). This treatment regimen resulted in the recovery of a smaller percentage of abnormal oocytes and embryos. However, the overall rate of blastocyst formation after culture in vitro and the birth rate after embryo transfer were not optimal. Further refinement of the superovulation strategies, such as the use of single or multiple injections of $\mathrm{FSH}$, treatment with $\mathrm{GnRH}$ antagonists, and the use of recombinant gonadotrophins, may ensure more balanced FSH:LH ratios, and thus improve the quality of oocytes and embryos produced. In general, determination of a satisfactory superovulation method in ferrets as reported here, which simplifies oocyte collection procedures, should benefit the future application of in vitro fertilization or somatic cell cloning in ferrets.

The present study is the first systematic analysis of the in vitro culture conditions required for the development of ferret embryos. CZB and TCM199/FBS, two of the most commonly used media for embryo culture in other species, provided optimum culture conditions, in which a high percentage of embryos developed to the morula or blastocyst stages in an atmosphere of $5 \% \mathrm{CO}_{2}$ and $95 \%$ air at $38.5^{\circ} \mathrm{C}$. However, embryos cultured in TCM199/FBS developed into blastocysts $12 \mathrm{~h}$ more rapidly than did embryos cultured in CZB. It is possible that the CZB medium contains factors that cause developmental delay in ferret embryos cultured in vitro. An incubation temperature of $38.5^{\circ} \mathrm{C}$ was chosen in accordance with the normal body temperature of ferrets $\left(37.8-39.4^{\circ} \mathrm{C}\right)$. The NCSU-23 medium, which is ideal for the development of pig embryos in vitro (Petters and Reed, 1991; Petters and Wells, 1993), produced significantly poorer results, despite the fact that ferret and pig embryos are similar in size, morphology and pigmentation. Chang (1968) reported that only morulae were found in the uterus of ferrets at day 6 after mating, and that blastocysts did not appear until day 7 after mating. This conclusion was supported by Marston and Kelly (1969), although Hamilton (1934) reported blastocyst formation at day 6 after mating. In the present study, embryos that had developed to the morula stage after culture in vivo could be identified at day 6 after mating, and blastocysts first appeared at day 7 after mating, thus supporting the findings of Chang (1968) and Marston and Kelly (1969). In addition, the timing of embryo development to the eight-cell stage (day 4 after mating) was identical for embryos developed in vivo and in vitro, indicating that the in vitro culture conditions used in the present study provided an environment similar to that found in vivo.

Hoechst 33342 staining of embryos cultured in vitro to different stages of development in TCM199/FBS revealed a positive correlation between the number of nuclei and the developmental stage observed under light microscopy, and 

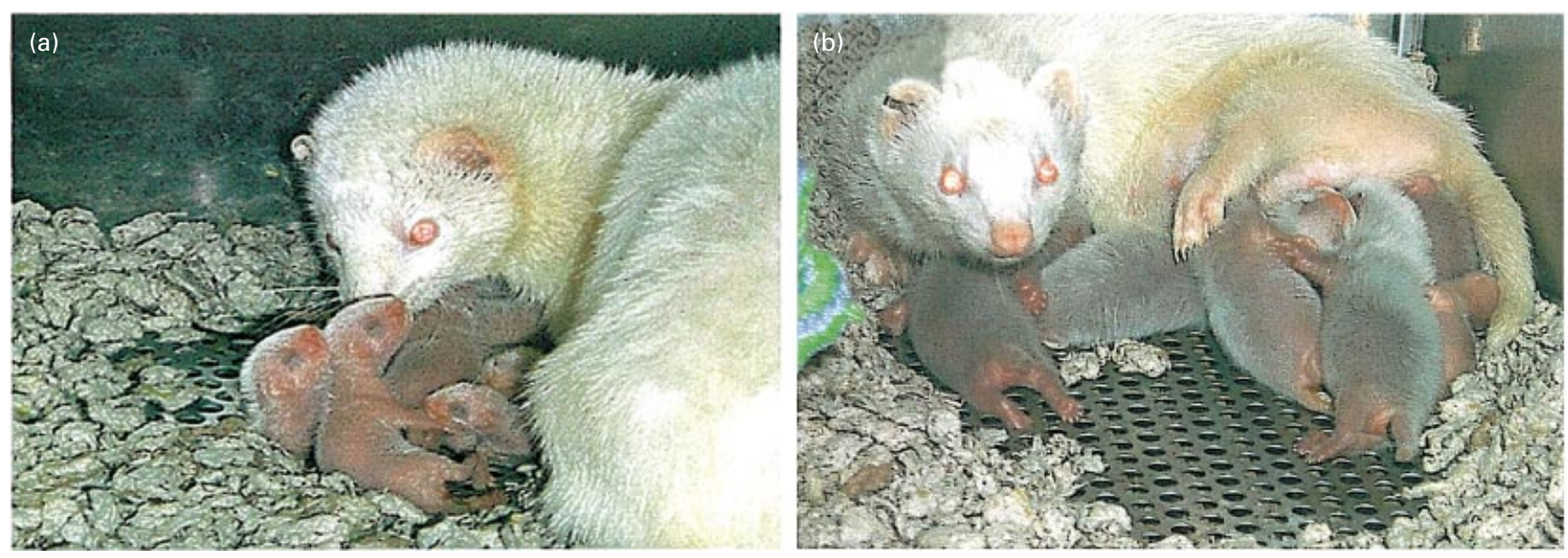

Fig. 2. Cinnamon-coloured ferret pups born to an albino surrogate female. Embryos from cinnamon-coloured ferrets were collected at the eight-cell stage at $100 \mathrm{~h}$ after hCG treatment and were transferred immediately into a pseudopregnant albino ferret that had mated with a vasectomized male. The photos of the cinnamon-coloured kits with their albino surrogate mother were taken at (a) day 4 and (b) day 18 after birth. The pigmented coats and nails of these pups (which darkened further as the kits matured) show prominent differences from those of their surrogate mother.

also indicated proper development. The average number of nuclei in embryos at the blastocyst stage, as determined in this study at the beginning of day 7 after hCG treatment, were in agreement with the findings of Kidder et al. (1999a), further demonstrating the ability of TCM199/FBS to support the development of ferret embryos in vitro. However, whether media tested in the present study will support the development of ferret embryos beyond the blastocyst stage remains to be elucidated. The percentage of live offspring produced after in vitro culture and embryo transfer was low, indicating that not all well-developed blastocysts under in vitro culture conditions have the potential to develop to term once transferred to the uterus. Further modification of in vitro culture conditions should provide better environmental conditions for development of ferret embryos.

The six embryo transfer experiments all resulted in pregnancy of the recipients and only one female failed to deliver live young. For the recipient that did not produce live kits, two dead kits of apparently normal development were found in the collection pan of the cage. It is possible that these kits had been pushed out of the nesting pan by the mother. The high rate of pregnancy in ferrets after embryo transfer is in agreement with the rate $(90 \%)$ reported by Kidder et al. (1999b). When eight-cell embryos were transferred immediately after harvest, the percentage of embryos that developed to term $(61 \%)$ was twice as high as that found after transfer of embryos cultured in vitro (32\%). One of the recipients of the embryos cultured in vitro gave birth to only one live and one dead kit, even though more fetuses were detected by palpation. Therefore, a Caesarean section was performed within $24 \mathrm{~h}$ after the start of the labour. Two more kits were delivered manually and, one was still alive. When the uterine horns were exposed, eight placental discs were found, indicating that resorption of at least four implanted embryos had occurred. In the only ferret that produced live young from all of the transferred embryos cultured in vitro, all embryos were delivered to the left uterine horn, whereas the other two ferrets received embryos in both uterine horns. Hence, it is possible that the increased surgical manipulation of the uterus results in increased trauma and aborted fetuses. Furthermore, under in vitro culture conditions considered optimal in this study, only $64 \%$ of the one- or two-cell embryos developed to the blastocyst stage. Although all eight-cell embryos cultured in vitro looked morphologically normal at the time of transfer, at least one-third lacked the ability to develop to term. It is also possible that the number of embryos transferred affects the overall efficiency of embryo transfer in ferrets. Ferrets in the wild generally ovulate six to ten oocytes and produce similar numbers of live kits. When six in vitro cultured embryos were transferred to females, all six embryos developed to term and survived beyond week 8 after birth. Therefore, transferring too many embryos at one time may adversely affect the chance of survival of individual embryos. However, when fresh embryos were transplanted, large numbers (13 and 11) of live kits were born, indicating that ferrets are capable of carrying more than ten embryos. Given the limited number of experiments to date, it is difficult to draw firm conclusions about the optimum number of embryos in a given transfer experiment.

In the present study, the overall survival rate of ferret kits after birth was low. A closer observation of the postnatal development of ferret kits revealed that a subgroup grew significantly more slowly than their siblings, mainly as a result of their inability to feed. These kits normally died within 2 weeks of birth. The relatively large litter size apparently contributed to the high mortality rate among newborns, as all kits in the two smallest litters (three and six) 
survived beyond week 8 . Other factors that may affect the success of embryo survival include seasonal variations in reproductive physiology, and the age and number of previous pregnancies.

In summary, experiments in the present study have begun to optimize parameters required for genetic manipulation of ferret embryos. This increased understanding of embryo development and transfer may allow for successful development of new animal models for genetic diseases using techniques such as somatic cell nuclear transfer and transgenic technology.

The authors wish to thank R. Scipioni and her staff at Marshall Farms for supplying the ferrets used in this study, as well as for a great deal of assistance with ferret care and reproduction. The authors also thank personnel in the University of lowa animal facility, for their effort in maintenance of the ferret colony; R. S. Prather and staff at the University of Missouri-Columbia for valuable technical assistance; and T. Ritchie for her help in preparing this manuscript. This research was partially funded by the Cystic Fibrosis Foundation (JIANG00G0) and the National Institutes of Health (DK47967, DK54759 and HL61234; JFE).

\section{References}

Amstislavskii S, Maksimovskii LF, Zudova GA and Ternovskaia lu G (1997) Superovulation induced by the administration of PMSG to mustelids Ontogenez 28 359-366

Chang MC (1965) Fertilizing life of ferret sperm in the female tract Journal of Experimental Zoology 158 87-100

Chang MC (1968) Reciprocal insemination and egg transfer between ferrets and mink Journal of Experimental Zoology 168 49-59

Chatot CL, Ziomek CA, Bavister BD, Lewis JL and Torres I (1989) An improved culture medium supports development of random-bred 1-cell mouse embryos in vitro. Journal of Reproduction and Fertility $\mathbf{8 6}$ 679-688

Curtis LN, Carson JL, Collier AM, Gambling TM, Hu SS, Leigh MW and Boat TF (1987) Features of developing ferret tracheal epithelium: ultrastructural observations of in vivo and in vitro differentiation of ciliated cells Experimental Lung Research 13 223-240

Day BN (1979) Embryo transfer in swine Theriogenology 11 27-31

Dickman Z (1982) Egg transfer in the mouse and rat. In Mammalian Egg Transfer pp 19-27 Ed. CE Adams. CRC Press, Inc., Boca Raton, FL

Duan D, Sehgal A, Yao J and Engelhardt JF (1998) Lef1 transcription factor expression defines airway progenitor cell targets for in utero gene therapy of submucosal gland in cystic fibrosis American Journal of Respiratory and Cell Molecular Biology 18 750-758

Durchfeld B, Baumgartner W and Krakowka S (1991) Intranasal infection of ferrets (Mustela putorius furo) with canine parainfluenza virus Zentralblatt Veterinarmedizine (B) 38 505-512

Ertzeid G and Storeng R (1992) Adverse effects of gonadotrophin treatment on pre- and postimplantation development in mice Journal of Reproduction and Fertility 96 649-655

Fenton RJ, Morley PJ, Owens IJ, Gower D, Parry S, Crossman L and Wong T (1999) Chemoprophylaxis of influenza A virus infections, with single doses of zanamivir, demonstrates that zanamivir is cleared slowly from the respiratory tract Antimicrobial Agents and Chemotherapy 43 2642-2647

Hamilton WJ (1934) The early stages in the development of the ferret. Fertilization to the formation of the pro-chordal plate Transactions Royal Society Edinburgh 58 251-278

Hammond J and Marshall FHA (1934) Oestrus and pseudopregnancy in the ferret Proceedings Royal Society London 105 607-638

Heape W (1890) Preliminary note on the transplantation and growth of mammalian ova within a uterine foster mother Proceedings Royal Society of London $\mathbf{4 8} 457-458$
Husseini RH, Collie MH, Rushton DI, Sweet C and Smith H (1983) The role of naturally-acquired bacterial infection in influenza-related death in neonatal ferrets British Journal of Experimental Pathology 64 559-569

Jakeman KJ, Rushton DI, Smith H and Sweet C (1991) Exacerbation of bacterial toxicity to infant ferrets by influenza virus: possible role in sudden infant death syndrome (published erratum appears in Journal of Infectious Disease 1991; 164 232) Journal of Infectious Disease 163 35-40

Kidder JD, Giles JR, Foote RH, Richmond ME and Salerno M (1999a) Allocation of inner cell mass and trophectoderm cells to the preimplantation blastocyst of the domestic ferret, Mustela putorius furo. Journal of Experimental Zoology 283 202-209

Kidder JD, Roberts PJ, Simkin ME, Foote RH and Richmond ME (1999b) Nonsurgical collection and nonsurgical transfer of preimplantation embryos in the domestic rabbit (Oryctolagus cuniculus) and domestic ferret (Mustela putorius furo) Journal of Reproduction and Fertility $\mathbf{1 1 6}$ 235-242

Kreamer DC, Flow BL, Schriver MD, Kinney GM and Pennycook JW (1979) Embryo transfer in the non-human primate, feline and canine Theriogenology 11 51-62

Leigh MW, Gambling TM, Carson JL, Collier AM, Wood RE and Boat TF (1986) Postnatal development of tracheal surface epithelium and submucosal glands in the ferret Experimental Lung Research $\mathbf{1 0}$ 153-169

Leigh MW, Connor RJ, Kelm S, Baum LG and Paulson JC (1995) Receptor specificity of influenza virus influences severity of illness in ferrets Vaccine 13 1468-1473

McLain DE, Harper SM, Roe DA, Babish JG and Wilkinson CF (1985) Congenital malformations and variations in reproductive performance in the ferret: effects of maternal age, colour and parity Laboratory Animal Science 35 251-255

Marston JH and Kelly WA (1969) Contraceptive action of intra-uterine devices in the ferret Journal of Reproduction and Fertility 18 419-429

Mead RA, Joseph MM and Neirinckx S (1988) Optimal dose of human chorionic gonadotrophin for inducing ovulation in the ferret Zoo Biology 7 263-267

Moor NW (1982) Egg transfer in the sheep and goat. In Mammalian Egg Transfer pp 119-133 Ed. CE Adams. CRC Press, Inc., Boca Raton, FL

Moor RM, Osborn JC and Crosby IM (1985) Gonadotrophin-induced abnormalities in sheep oocytes after superovulation Journal of Reproduction and Fertility 74 167-172

Newcomb R (1982) Egg recovery and transfer in cattle. In Mammalian Egg Transfer pp 81-119 Ed. CE Adams. CRC Press, Inc., Boca Raton, FL

Nicholas JS (1993) Development of transplanted rat eggs Proceedings Society of Experimental Biololy and Medicine 30 1111-1113

Petters RM and Reed ML (1991) Addition of taurine or hypotaurine to culture medium improves development of one- and two-cell pig embryos in vitro. Theriogenology 35253

Petters RM and Wells KD (1993) Culture of pig embryos Journal of Reproduction and Fertility Supplement 48 61-73

Plopper CG, Hill LH and Mariassy AT (1980) Ultrastructure of the nonciliated bronchiolar epithelial (Clara) cell of mammalian lung. III. A study of man with comparison of 15 mammalian species Experimental Lung Research 1 171-180

Robinson A (1918) The formation, rupture and closure of ovarian follicles in ferrets and ferret-polecat hybrids and some associated phenomena Transactions Royal Society Edinburgh 52 303-362

Sehgal A, Presente A and Engelhardt JF (1996) Developmental expression patterns of CFTR in ferret tracheal surface airway and submucosal gland epithelia American Journal of Respiratory Cell and Molecular Biology 15 122-131

Whyman D and Moore RW (1980) Effects of PMSG and the prostaglandin $F_{2}$ alpha analogue, cloprostenol, on superovulation, fertilization and egg transport in the ewe Journal of Reproduction and Fertility $\mathbf{6 0} 267-272$

Received 14 December 2000.

First decision 12 March 2001.

Revised manuscript received 16 May 2001.

Accepted 7 June 2001. 